Article

\title{
Experimental and Model Study on Raw Biomass Gasification Syngas Conditioning in a Molten $\mathrm{NaOH}-\mathrm{Na}_{2} \mathrm{CO}_{3}$ Mixture
}

\author{
Xiaobo Wang 1,2,3, Anqi Liu 1,2,3, Zengli Zhao 1,2,3,* and Haibin Li 1,2,3 \\ 1 Guangzhou Institute of Energy Conversion, Chinese Academy of Sciences, Guangzhou 510640, China; \\ wangxb@ms.giec.ac.cn (X.W.); liuaq@ms.giec.ac.cn (A.L.); lihb@ms.giec.ac.cn (H.L.) \\ 2 CAS Key Laboratory of Renewable Energy, Guangzhou 510640, China \\ 3 Guangdong Provincial Key Laboratory of New and Renewable Energy Research and Development, \\ Guangzhou 510640, China \\ * Correspondence: zhaozl@ms.giec.ac.cn; Tel.: +86-20-87057721
}

Received: 8 June 2020; Accepted: 12 July 2020; Published: 16 July 2020

\begin{abstract}
Raw syngas conditioning using molten salts was carried out in a fixed-bed reactor. The effects of the reaction conditions, including temperature, gas velocity, bubble diameter, molten salt static liquid heights, and inlet gas composition, on the composition of the syngas product and the properties of the spent molten salts were investigated. The molten salt absorbed $\mathrm{CO}_{2}$ in all of the experiments (at temperatures from $350{ }^{\circ} \mathrm{C}$ to $500^{\circ} \mathrm{C}$ ) and decreased its concentration down to $1 \%$. The $\mathrm{H}_{2} / \mathrm{CO}$ increased from 0.94 to a maximum of 11.0, which may meet most of the synthetic process' requirements. The temperature, gas velocity, and molten salt static liquid heights had significant effects on the $\mathrm{H}_{2}$ and $\mathrm{CO}$ concentrations in the gas product. Molten salt raw syngas conditioning can be a suitable follow-up procedure for gasification and pyrolysis.
\end{abstract}

Keywords: molten salts; syngas; conditioning; biomass; model

\section{Introduction}

The main components of syngas are $\mathrm{CO}$ and $\mathrm{H}_{2}$, which are used in the chemical industry for power generation and hydrogen production. There are many processes and means to produce syngas. Coal, natural gas, biomass, solid waste, and other carbon-containing fuels can be used to produce syngas via gasification or pyrolysis. As renewable energy sources are playing more important roles in global energy production, much work is focused on biomass (including solid waste), the only source of renewable energy that has the potential to replace fossil fuel. The typical gasification and pyrolysis temperatures of biomass and solid waste range between $700{ }^{\circ} \mathrm{C}$ and $900{ }^{\circ} \mathrm{C}$ [1-4]. The produced raw syngas has a temperature of $400-600{ }^{\circ} \mathrm{C}$; a relatively low $\mathrm{H}_{2} / \mathrm{CO}$ ratio, which is usually less 1.0 ; and a high $\mathrm{CO}_{2}$ content. These are disadvantages for the follow-up Fischer-Tropsch synthesis process and other synthesizing procedures.

There are two conventional ways of increasing the $\mathrm{H}_{2} / \mathrm{CO}$ ratio and decreasing the $\mathrm{CO}_{2}$ to make the syngas content meet the requirements of follow-up synthesis procedures. One way is through introducing steam into the gasification system, which usually decreases the reactor temperature and increases the $\mathrm{CO}_{2}$ content of raw syngas and requires a follow-up $\mathrm{CO}_{2}$ separation procedure. The other way is through using in situ absorption of $\mathrm{CO}_{2}$ and driving the water-gas shift reaction in the direction of $\mathrm{H}_{2}$ generation and $\mathrm{CO}$ consumption. Currently, much research is focused on $\mathrm{CaO}\left(\mathrm{Ca}(\mathrm{OH})_{2}\right)$ or minerals rich in $\mathrm{CaO}$ [5-7]. The optimal absorption reaction temperature for these kinds of absorbents is approximately $700^{\circ} \mathrm{C}$. At low temperatures, the absorbent has low reactivity, but when the temperature 
exceeds $900^{\circ} \mathrm{C}$, the absorption product, $\mathrm{CaCO}_{3}$, begins to decompose. Normally, the reaction must be pressurized for better performance [8].

Molten salts have the advantage of stability at high temperatures, low vapor pressure for a wide temperature range, high heat capacity, low viscosity, and absorptive capacity for $\mathrm{HCl}$ and $\mathrm{H}_{2} \mathrm{~S}$ from a high-temperature gas [9]. Molten salts are now widely used in material preparation, heat storage, nuclear engineering, coal gasification, solid waste disposal, and other fields [10]. $\mathrm{CO}_{2}$ [11] and acidic pollutants [12] (such as $\mathrm{H}_{2} \mathrm{~S}$ and $\mathrm{HCl}$ ) can be absorbed and stabilized in molten salts. Molten salt with components of $8.3 \mathrm{wt} \% \mathrm{Na}_{2} \mathrm{CO}_{3}$ and $91.7 \mathrm{wt} \% \mathrm{NaOH}$ has a low eutectic temperature of $285^{\circ} \mathrm{C}$ [10] and a relatively high boiling temperature $\left(>1000^{\circ} \mathrm{C}\right)$, which makes this kind of molten mixture suitable for follow-up purification and condition processing for biomass gasification. Other studies $[13,14]$ also showed that, at moderate reaction conditions, the gas produced from the pyrolysis of carbonaceous matter became richer in $\mathrm{H}_{2}$ content and lower in $\mathrm{CO}_{2}$ content. $\mathrm{CO}_{2}$ and acidic pollutants were removed by adding specific molten salts that were rich in $\mathrm{NaOH}$. Gas purification and gas content adjustment using molten salts rich in $\mathrm{NaOH}$ are promising methods of raw syngas conditioning. In fact, there are different opinions about molten mixtures that are rich in strong alkaline substances, which are called molten alkali [14] or molten salts [13].

Only a small amount of work related to syngas conditioning using molten salt mixtures has been published in the research literature [13]. Li et al. [14], Jiang et al. [15], and Wu et al. [15] investigated biomass gasification with molten salts that were rich in a strong alkaline substance, such as $\mathrm{NaOH}$ or $\mathrm{KOH}$, and $\mathrm{H}_{2} / \mathrm{CO}$ was dramatically increased in all cases. However, all of them considered added molten salts as a catalyst for biomass gasification and did not use added molten salts for the absorbent and catalyst of syngas conditioning. In the present work, the effects of molten salts on the raw syngas composition were studied using a fixed-bed reactor at temperatures between $350{ }^{\circ} \mathrm{C}$ and $500{ }^{\circ} \mathrm{C}$, which are typical raw syngas temperatures for solid waste and biomass pyrolysis/gasification, and the influencing factors of the conditioning process for creating syngas were investigated in detail and the mathematical model of the conditioning process was established for the first time.

\section{Experimental Procedure and Testing Method}

\subsection{Molten Salt Preparation}

The molten salt composition and properties are listed in Table 1. Inorganic salts $(99.5 \%$ pure $\mathrm{Na}_{2} \mathrm{CO}_{3}$ and $99 \%$ pure $\mathrm{NaOH}$ ) (Supplier: Aladdin) were used to make the molten salt mixture. The preparation procedures for the molten salt mixture were as follows: First, the powdered inorganic salts were mixed in the specific proportion shown in Table 1. Next, we put the mixture into the fixed bed and heated it to $700{ }^{\circ} \mathrm{C}$ with $\mathrm{N}_{2}$ introduced at $0.5 \mathrm{~L} / \mathrm{min}$ for $30 \mathrm{~min}$ to ensure that the salts were completely molten and mixed. Finally, the molten salts were cooled and stored for use.

Table 1. Composition and properties of the molten salts.

\begin{tabular}{cccc}
\hline Molten Salts Composition (wt $\%)$ & Eutectic Temperature $\left({ }^{\circ} \mathbf{C}\right)$ & Amount $(\mathbf{g})$ & Nomenclature \\
\hline $8.3 \% \mathrm{Na}_{2} \mathrm{CO}_{3}$ and $91.7 \% \mathrm{NaOH}$ & 285 & $350-600$ & $\mathrm{NN}$ \\
\hline
\end{tabular}

\subsection{Raw Syngas Preparation}

According to the literature [1-4], gas with $35.25 \% \mathrm{CO}, 31.45 \% \mathrm{CO}_{2}$, and $33.30 \% \mathrm{H}_{2}\left(\mathrm{H}_{2} / \mathrm{CO}\right.$ at 0.94) was used as the sample raw syngas for biomass (including solid waste) gasification by ignoring trace gases, such as $\mathrm{H}_{2} \mathrm{~S}, \mathrm{NH}_{3}$, and other content that might exist in real raw syngas. The cylinder gas, which remained stable in terms of gas content and pressure, was used as a simulant gas source. The gas facilitated the analysis of the influence of reaction conditions, such as temperature, gas velocity, bubble diameter, and so on. Furthermore, we focused on the relations between $\mathrm{CO}, \mathrm{H}_{2}$, and $\mathrm{CO}_{2}$ during the experimental and model analysis. 


\subsection{Experimental Apparatus}

Raw syngas conditioning experiments were carried out in a fixed-bed reactor, as shown in Figure 1. The reactor mainly included the gas inlet, a reaction tube $(\varphi 70 \mathrm{~mm} \times 400 \mathrm{~mm}$, stainless steel 316L) containing molten salts, the electric furnace, and a gas outlet, among other components. A specially designed plate was placed at the end of the inlet tube to break the inlet gas down into small bubbles such that there was a better contact between the raw syngas and the molten salts for the reactions to take place. The reaction tube was placed into the electronic furnace and heated to a specific temperature. When the temperature reached a specific value, raw syngas was introduced into the reaction tube at a set flux via a mass flowmeter for $30 \mathrm{~min}$, and the gas product was sampled and then analyzed using Gas Chromatograph (GC).

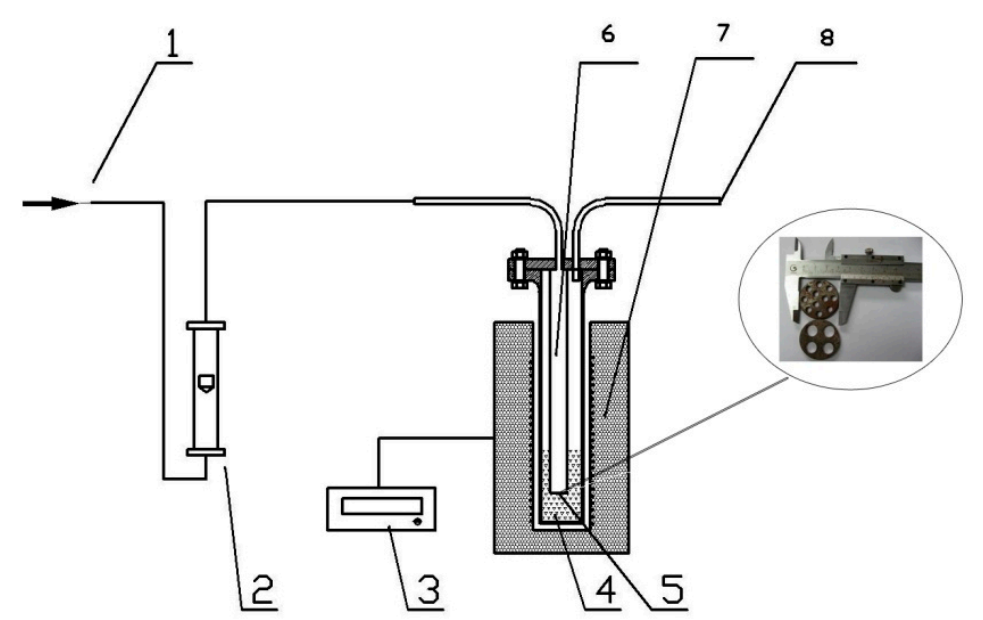

Figure 1. Schematic of the molten salt reactor setup: 1-gas inlet, 2 -flowmeter, 3 -thermal couple, 4-molten salts, 5-plate, 6-reaction tube, 7-electric furnace, 8-gas sampling outlet.

\subsection{Reaction Conditions}

Two kinds of specially designed plates, each having a hole with a diameter of $\Phi=5.0 \mathrm{~mm}$ or $\Phi=10.0 \mathrm{~mm}$, were placed at the end of the inlet tube to study the influence of the hole diameter. The plates were designed to have different hole opening diameters but with the same total orifice area such that the inlet gas velocity remained identical when other experimental conditions were the same.

The influence of the reaction conditions on the gas product was studied. These conditions included the molten salt temperature $\left(350-500{ }^{\circ} \mathrm{C}\right)$, the superficial gas velocity $(1.18-5.90 \mathrm{~mm} / \mathrm{s})$, and the plate position relative to the molten salt static liquid heights $(-15$ to $35 \mathrm{~mm})$. The defined reaction conditions were a temperature of $400{ }^{\circ} \mathrm{C}$, plate position of $15 \mathrm{~mm}$, and a superficial gas velocity of $2.95 \mathrm{~mm} / \mathrm{s}$, unless otherwise mentioned.

\subsection{Testing Methods}

A GC-20B-1 (Shimadzu Corporation, Kyoto, Japan) was used to analyze the gas composition. The GC-20B-1 has a thermal conductivity detector (TCD), which has a temperature of $80{ }^{\circ} \mathrm{C}$ and an electric current of $60 \mathrm{~mA}$. The capillary column was a GS-Carbon plot $(30 \mathrm{~m} \times 0.530 \mathrm{~mm} \times 3.001 \mu \mathrm{m})$, with a column temperature of $65^{\circ} \mathrm{C}$. The carrier gas was $99.995 \% \mathrm{He}$, the gas pressure was $0.2 \mathrm{MPa}$, and the flux was $77.5 \mathrm{~mL} / \mathrm{min} . \mathrm{H}_{2}, \mathrm{O}_{2}, \mathrm{~N}_{2}, \mathrm{CH}_{4}, \mathrm{CO}, \mathrm{CO}_{2}, \mathrm{C}_{2} \mathrm{H}_{4}$, and $\mathrm{C}_{2} \mathrm{H}_{6}$ could be detected using an internal standard method with standard gas.

The $\mathrm{NaOH}$ and $\mathrm{Na}_{2} \mathrm{CO}_{3}$ content in molten salts were measured using standard DL 425.2-1991 (sodium hydroxide and sodium carbonate content in industrial sodium hydroxide—titration). 


\section{Results and Discussion}

\subsection{Influence of the Reaction Conditions on the Gas Product Content}

\subsubsection{Influence of Temperature on the Gas Product}

The syngas product composition changed dramatically when the molten salt temperature rose. As shown in Figure 2, under all reaction temperatures, the gas product had a higher $\mathrm{H}_{2}$ content and a lower $\mathrm{CO}$ content with smaller plate openings. Between $350{ }^{\circ} \mathrm{C}$ and $500{ }^{\circ} \mathrm{C}$, the main content of the gas products, namely, $\mathrm{H}_{2}$ and $\mathrm{CO}$, varied from $61.6-72.6 \%$ and $24.8-38.1 \%$, respectively. At all experimental temperatures, the $\mathrm{CO}_{2}$ content was less than $1.8 \% . \mathrm{H}_{2}$ and $\mathrm{CO}$ exhibited a trend that was directly related to temperature. The $\mathrm{H}_{2} / \mathrm{CO}$ ratio increased from 0.94 to between 1.5 and 2.9, which can meet the requirements of most synthetic processes.

There are different opinions on how molten salts that are rich in strong alkaline substances (such as $\mathrm{NaOH}$ ) promote hydrogen production. Some researchers $[14,15]$ believe that it is the catalysis effect of cations and anions in the molten salt mixture. However, the catalytic effects give no reasonable explanation for the hydrogen production rate that exceeds the maximal theoretical yield in some cases $[16,17]$.

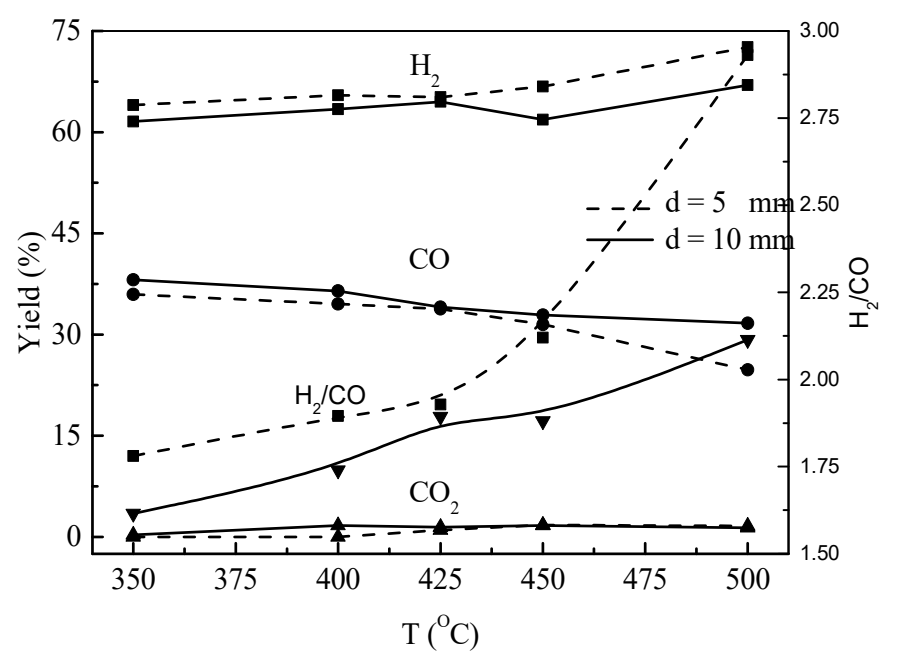

Figure 2. The influence of temperature on the syngas composition (plate position: $15 \mathrm{~mm}$, superficial gas velocity: $2.95 \mathrm{~mm} / \mathrm{s}$ ).

As shown in Figure 3, Raw syngas conditioning occurs when the raw syngas is introduced into molten salts and breaks down into small gas bubbles. This process can be described using two main reactions acting at the same time:

A. At the surface of the gas bubbles: Driven by a concentration difference, $\mathrm{CO}_{2}$ in the bubbles is transmitted from the inside of the bubble to the surface, where it reacts with $\mathrm{NaOH}$ in the molten salts:

$$
\mathrm{NaOH}+\mathrm{CO}_{2} \stackrel{\text { melting }}{\rightarrow} \mathrm{Na}_{2} \mathrm{CO}_{3}+\mathrm{H}_{2} \mathrm{O}(\mathrm{g}) .
$$

B. Inside the bubbles: Because $\mathrm{CO}_{2}$ is consumed, the water-gas reaction shifts in the direction of $\mathrm{CO}$ consumption and generating $\mathrm{CO}_{2}$ and $\mathrm{H}_{2}$ generation:

$$
\mathrm{CO}+\mathrm{H}_{2} \mathrm{O}(\mathrm{g}) \leftrightarrow \mathrm{CO}_{2}+\mathrm{H}_{2}
$$


The overall process is the following reaction:

$$
\mathrm{CO}+\mathrm{NaOH} \stackrel{\text { melting }}{\rightarrow} \mathrm{Na}_{2} \mathrm{CO}_{3}+\mathrm{H}_{2}
$$

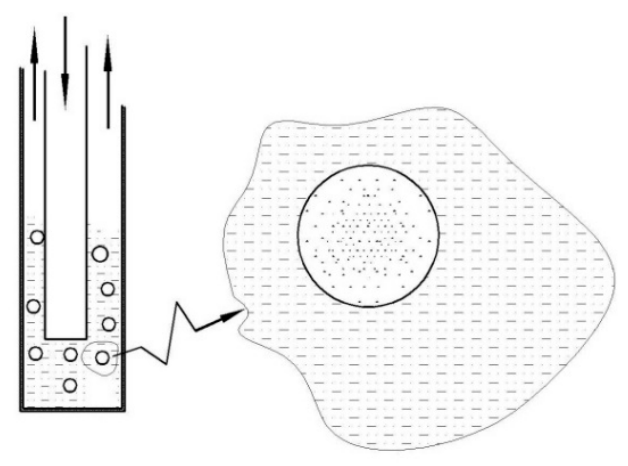

Figure 3. Schematic of syngas conditioning using molten salts.

When the molten salt temperature rises, the rates of reactions (1) (2) increase and accelerate the $\mathrm{CO}$ conversion to $\mathrm{H}_{2}$. Some researchers $[8,18]$ have used $\mathrm{CaO}$ for the absorption of $\mathrm{CO}_{2}$ at $3 \mathrm{MPa}$ and $650^{\circ} \mathrm{C}$ and produced gas with a similar composition to that presented here. However, the experimental conditions in this paper are much more moderate.

\subsubsection{Influence of the Superficial Gas Velocity on the Gas Product Content}

When the superficial gas velocity varied between $1.18 \mathrm{~mm} / \mathrm{s}$ and $5.90 \mathrm{~mm} / \mathrm{s}$, the $\mathrm{H}_{2}$ and CO content in the gas product ranged from $57.8-89.4 \%$ and $8.1-41.2 \%$, respectively, after the raw syngas reacted with the molten salts. The experimental results are shown in Figure 4 . As the superficial gas velocity increased, the $\mathrm{H}_{2}$ content decreased and the $\mathrm{CO}$ content increased. While the superficial gas velocity was less than $3.0 \mathrm{~mm} / \mathrm{s}$, the gas product had more $\mathrm{H}_{2}$ and less $\mathrm{CO}$ content with smaller plate holes. The maximum $\mathrm{H}_{2} / \mathrm{CO}$ ratio was 11.0, which is an impossible value for conventional steam reforming conditioning processes $[3,18]$. While the superficial gas velocity was greater than $4.0 \mathrm{~mm} / \mathrm{s}$, there was a minimal difference between the effect of plates with different hole diameters. When the superficial gas velocity was greater, the gas residence time in the molten salt was shorter, which reduced the diffusion time of the $\mathrm{CO}_{2}$ in the gas bubbles, the reaction time of the $\mathrm{CO}_{2}$ absorption reaction (1), and the water-gas balance reaction (2). Moreover, when more gas bubbles enter the molten salt, small bubbles tended to merge into larger ones [19]. The mass transfer distance of $\mathrm{CO}_{2}$ in the gas bubbles became longer, which made it difficult to transfer $\mathrm{CO}_{2}$ from inside the bubbles to the surface of the bubbles. As a result, this effect influenced the balance of the water-gas shift reaction (2). All of these influences slowed down the conversion of $\mathrm{CO}$ to $\mathrm{H}_{2}$ in the raw syngas, as shown in reaction (3). 


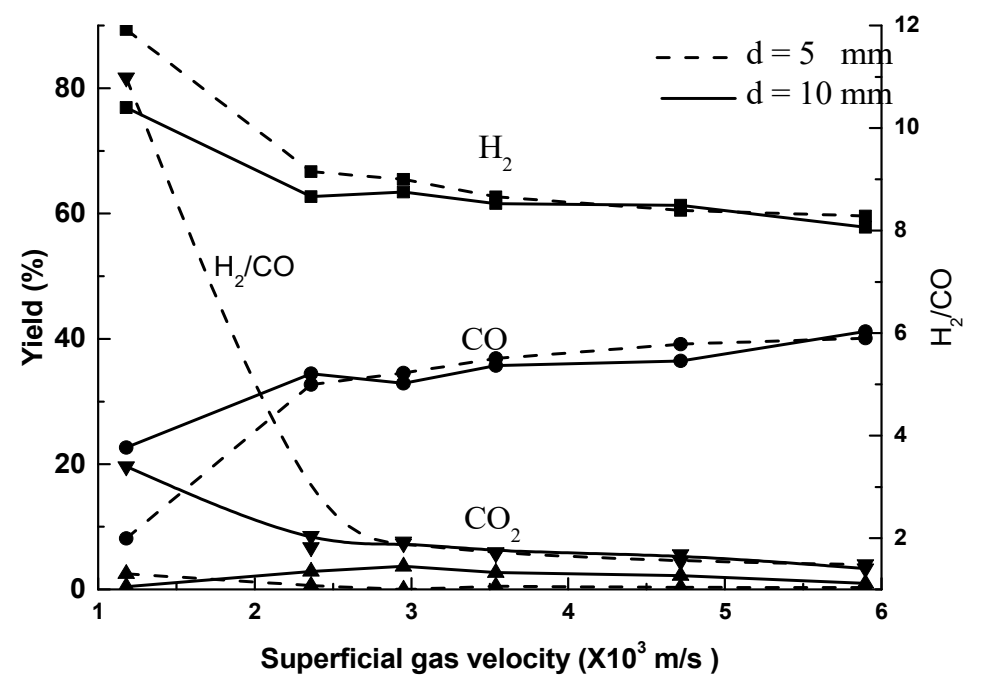

Figure 4. Syngas composition as a function of gas the velocity (temperature: $400{ }^{\circ} \mathrm{C}$, plate position: $15 \mathrm{~mm}$ ).

\subsubsection{Influence of the Molten Salt's Static Liquid Height on the Gas Product Content}

A coordinate system was established by putting the origin at plate 5, as shown in Figure 1, and defining the upward direction as positive. The influence of the molten salt static liquid height on the gas product content was studied. As shown in Figure 5, for plate with hole diameter $10 \mathrm{~mm}$, the $\mathrm{H}_{2}$ and $\mathrm{CO}$ content in the gas product was $60.8-71.7 \%$ and $24.8-39.2 \%$, respectively, when the plate position varied between $-15 \mathrm{~mm}$ and $35 \mathrm{~mm}$. Under all experimental conditions, the $\mathrm{CO}_{2}$ content in the gas product was less than $2 \%$.

When the plate position was between $-15 \mathrm{~mm}$ and $0 \mathrm{~mm}$, the gas inlet plate 5 was not in contact with the molten salts. The $\mathrm{CO}_{2}$ in the raw syngas made contact with the molten salt liquid surface and reacted with the $\mathrm{NaOH}$. As expected, there was minimal change in the gas product content with changes in the plate position. When the plate position was between $0 \mathrm{~mm}$ and $35 \mathrm{~mm}$, the gas inlet plate 5 was immersed in the molten salt, and raw syngas entered the molten salt through the plate and formed small gas bubbles. There was more $\mathrm{H}_{2}$ and less $\mathrm{CO}$ in the gas produced when the plate was lowered into the molten salt.

The retention time was predicted to increase when the plate was put deeper into the molten salt [20]. The reaction time for reactions (1) and (2) increased, which converted more $\mathrm{CO}$ to $\mathrm{H}_{2}$ in the system. Three forces, namely, gravity, buoyancy, and viscous forces, act on the gas bubbles that move in a static liquid. If the velocity $v$ of the gas bubble is small and the space around the gas bubble can be assumed to be infinite, then the Stokes formula, which describes the viscous force, can be deduced from the turbulent flow around the sphere:

$$
F=\frac{1}{8} C_{D} \rho_{l} \pi v^{2} d^{2}
$$

When the Reynolds number is relatively small, $C_{D}$ can be approximated as:

$$
C_{D}=\frac{12}{R e}, R e=\frac{\rho_{l} d v}{2 \mu} .
$$

While the bubble rises for a short distance, the three forces will become balanced [21] such that the bubble will rise at a steady velocity $v_{0}$, where the forces balance as follows:

$$
\frac{1}{6} \pi d^{3}\left(\rho_{l}-\rho_{0}\right) g=3 \pi \mu v_{0} d
$$




$$
v_{0}=\frac{d^{2}\left(\rho_{l}-\rho_{0}\right) g}{18 \mu}
$$

Furthermore, the residence time of the bubble inside the molten liquid can be estimated as:

$$
t=\frac{l}{v_{0}}=\frac{18 \mu l}{d^{2}\left(\rho_{l}-\rho_{0}\right) g}
$$

Because the viscosity coefficient of the molten mixture is on the order of $10^{-3}$, the residence time of the bubble in the molten liquid is on the order of $1 \mathrm{~s}$.

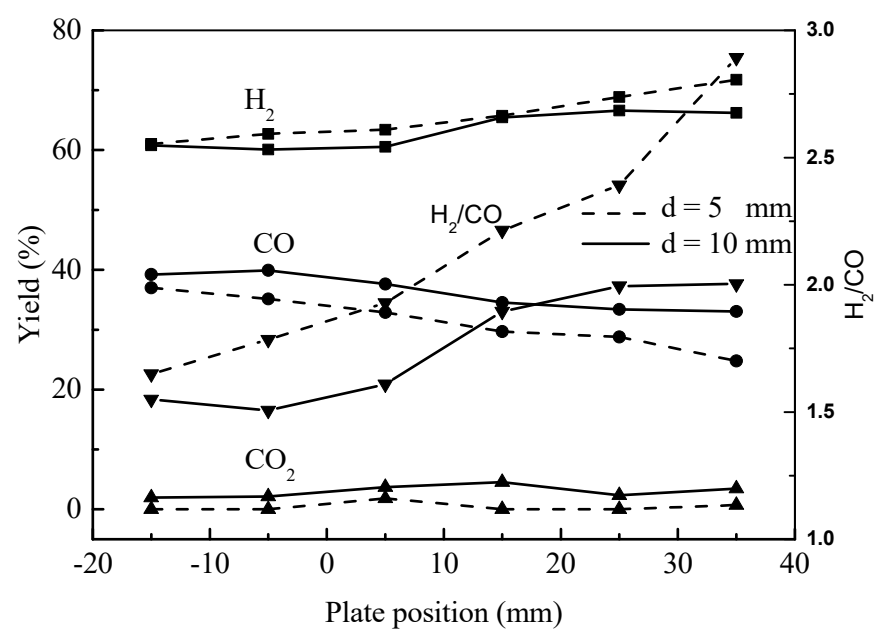

Figure 5. Syngas composition as a function of molten salt addition (temperature: $400{ }^{\circ} \mathrm{C}$, superficial gas velocity: $2.95 \mathrm{~mm} / \mathrm{s}$ ).

\subsubsection{Influence of the Conditioning Process on the Molten Salts}

An 11-hour experiment was conducted to study the stability of the molten salt raw syngas conditioning. As shown in Figure 6, the gas product content was relatively stable throughout the experiment; the $\mathrm{H}_{2}$ and $\mathrm{CO}$ contents ranged between $65.8 \%$ and $33.7 \%$, respectively, and the $\mathrm{CO}_{2}$ content was stable at $0.4 \%$. Solidified molten salts were taken out after cooling. As shown in Figure 7 , the salt mixture coagulum was a reddish color because small amounts of Fe oxides were mixed into it.

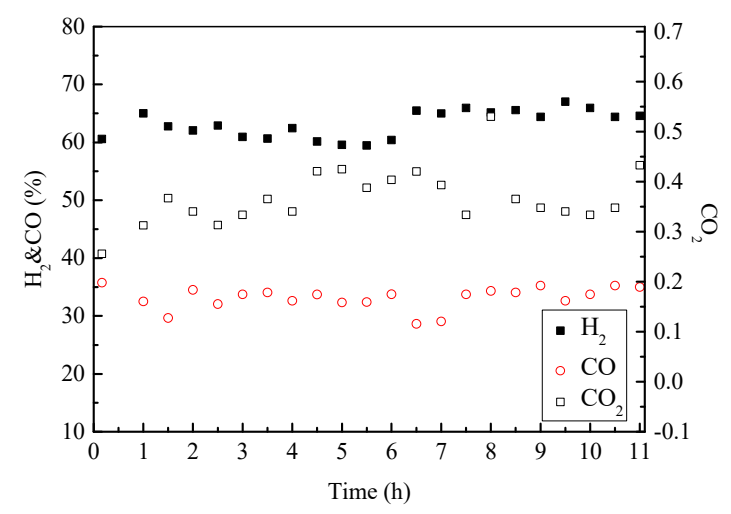

Figure 6. Syngas composition as a function of time (temperature: $400{ }^{\circ} \mathrm{C}$, plate position: $15 \mathrm{~mm}$, superficial gas velocity: $2.95 \mathrm{~mm} / \mathrm{s}$ ). 


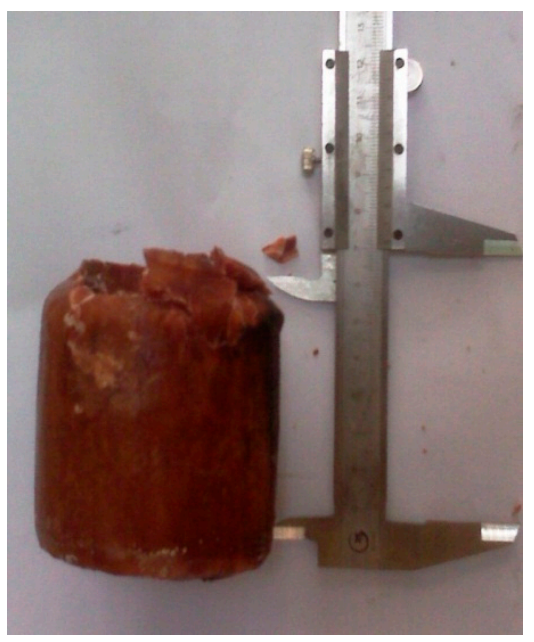

Figure 7. Picture of the molten salt after reacting for $11 \mathrm{~h}$.

The solidified molten salt, shown in Figure 7, was cut into eight slices from bottom to top and two slices from the inside to the outside. The original molten salt content was $91.7 \mathrm{wt} \% \mathrm{NaOH}$ and $8.3 \mathrm{wt} \% \mathrm{Na}_{2} \mathrm{CO}_{3}$. After the experiment, the average molten salt content was $37.7 \mathrm{wt} \% \mathrm{NaOH}$ and $62.3 \mathrm{wt} \% \mathrm{Na}_{2} \mathrm{CO}_{3}$ for the outer slice and $35.9 \mathrm{wt} \% \mathrm{NaOH}$ and $64.1 \mathrm{wt} \% \mathrm{Na}_{2} \mathrm{CO}_{3}$ for the inner slice, as shown in Figure 8. The $\mathrm{NaOH}$ in the molten salt absorbed $\mathrm{CO}_{2}$ and converted it into $\mathrm{Na}_{2} \mathrm{CO}_{3}$. This conversion occurred in the outer slice slightly more than that in the inner slice. The highest $\mathrm{NaOH}$ content appeared at $45 \mathrm{~mm}$ in the molten salt where plate 5 was placed in the experiment, as shown in Figure 1. From the $45 \mathrm{~mm}$ slice to the top or the bottom of the molten salts, the $\mathrm{Na}_{2} \mathrm{CO}_{3}$ content increased, and the majority of the $\mathrm{Na}_{2} \mathrm{CO}_{3}$ was found in the top layer of the molten salts. This result may have occurred because raw syngas stayed at the molten salt surface after the gas bubbles broke and continued to react with the molten salts, as in reaction (3), which converted $\mathrm{NaOH}$ to $\mathrm{Na}_{2} \mathrm{CO}_{3}$ by absorbing $\mathrm{CO}_{2}$. Moreover, the density of $\mathrm{Na}_{2} \mathrm{CO}_{3}$ is $2.54 \mathrm{~g} / \mathrm{cm}^{3}$, which is slightly greater than the density of $\mathrm{NaOH}\left(2.13 \mathrm{~g} / \mathrm{cm}^{3}\right)$ [22,23]. During the experiment, $\mathrm{Na}_{2} \mathrm{CO}_{3}$ gradually sunk to the bottom of the reactor.

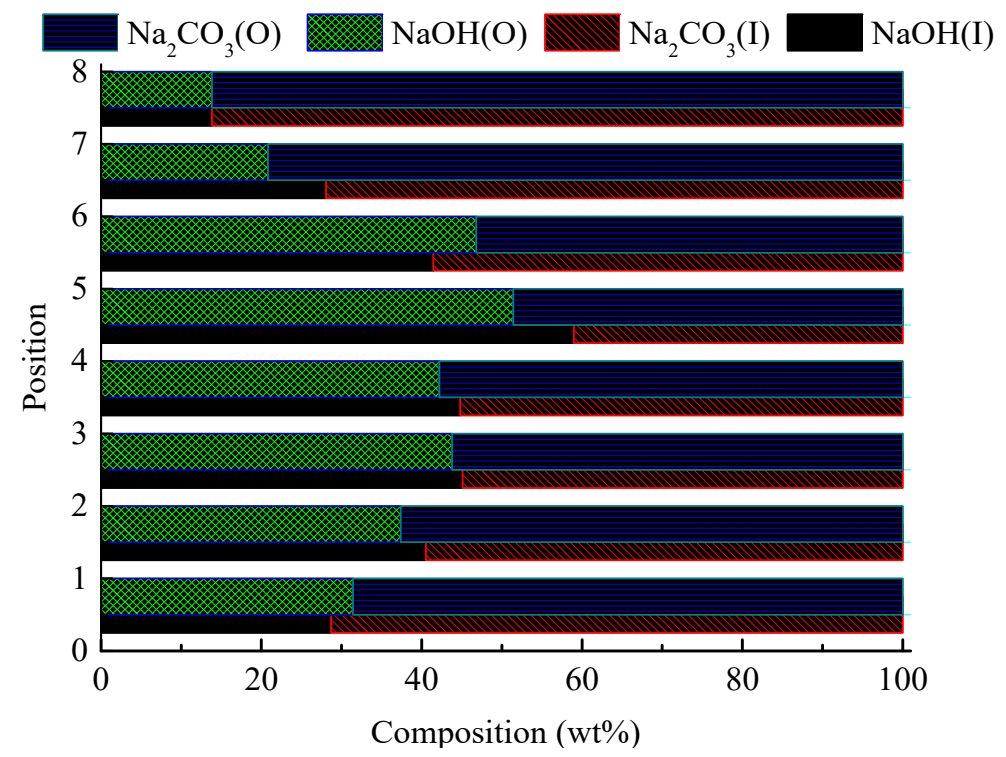

Figure 8. Composition of the molten salts after reacting for $11 \mathrm{~h}$ (temperature: $400{ }^{\circ} \mathrm{C}$, plate position: $45 \mathrm{~mm}$, superficial gas velocity: $2.95 \mathrm{~mm} / \mathrm{s}$ ). 
Figures 9 and 10 show the phase diagram and the DSC (Differential Scanning Calorimetry) differential curve (DDSC) of the NN molten salt mixture. It can be seen that when the molar ratio of $\mathrm{NaOH}$ and $\mathrm{Na}_{2} \mathrm{CO}_{3}$ varied between 9:1 and 7:3, the $\mathrm{NN}$ molten salt endothermic peak temperature was almost the same. NN molten salt has only two endothermic peaks: the first endothermic peak is near $100^{\circ} \mathrm{C}$, which is because $\mathrm{NN}$ molten salt absorbs water easily, where this peak is the endothermic peak of the evaporation of water and decomposition of sodium carbonate hydrate in the molten salt; the second endothermic peak is around $292^{\circ} \mathrm{C}$, and the peak temperature was slightly higher than the literature value of the melting point of $\mathrm{NN}$ molten salt. It can be seen that for $\mathrm{NaOH}: \mathrm{Na}_{2} \mathrm{CO}_{3}$ molar ratios in the range of 9:1-7:3, $\mathrm{NN}$ will partially melt around $292^{\circ} \mathrm{C}$, where unmelted $\mathrm{NaOH}$ or $\mathrm{Na}_{2} \mathrm{CO}_{3}$ will disperse in the liquid molten salt under gas agitation to form a turbid suspension mixture.

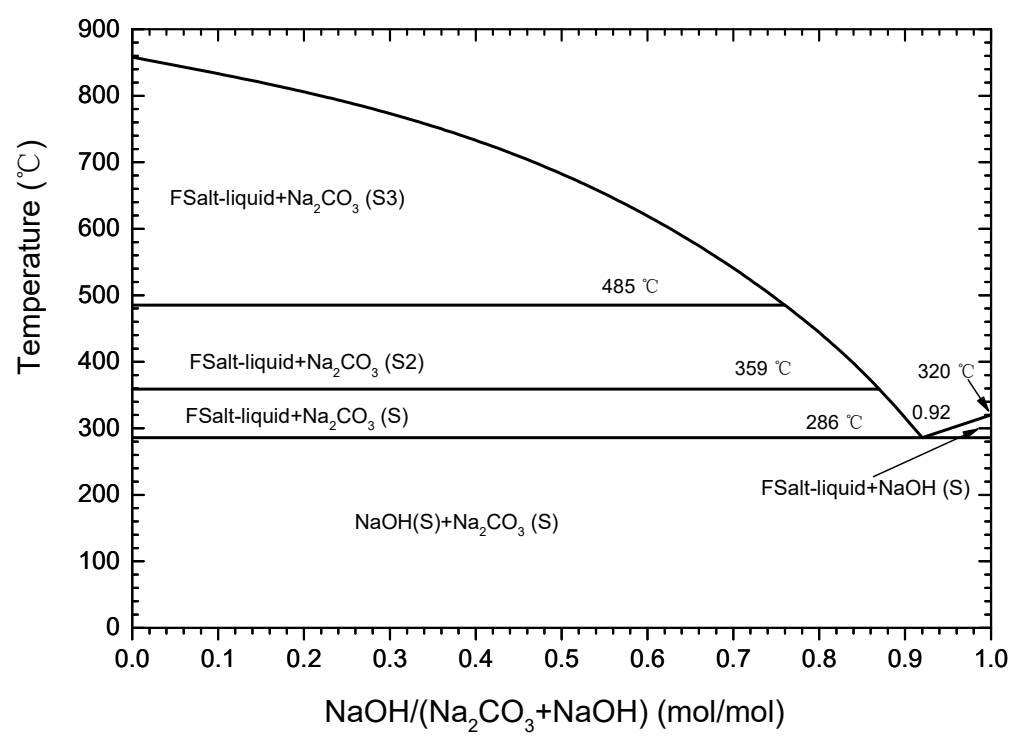

Figure 9. Phase diagram of $\mathrm{NaOH}$ and $\mathrm{Na}_{2} \mathrm{CO}_{3}$ mixtures.

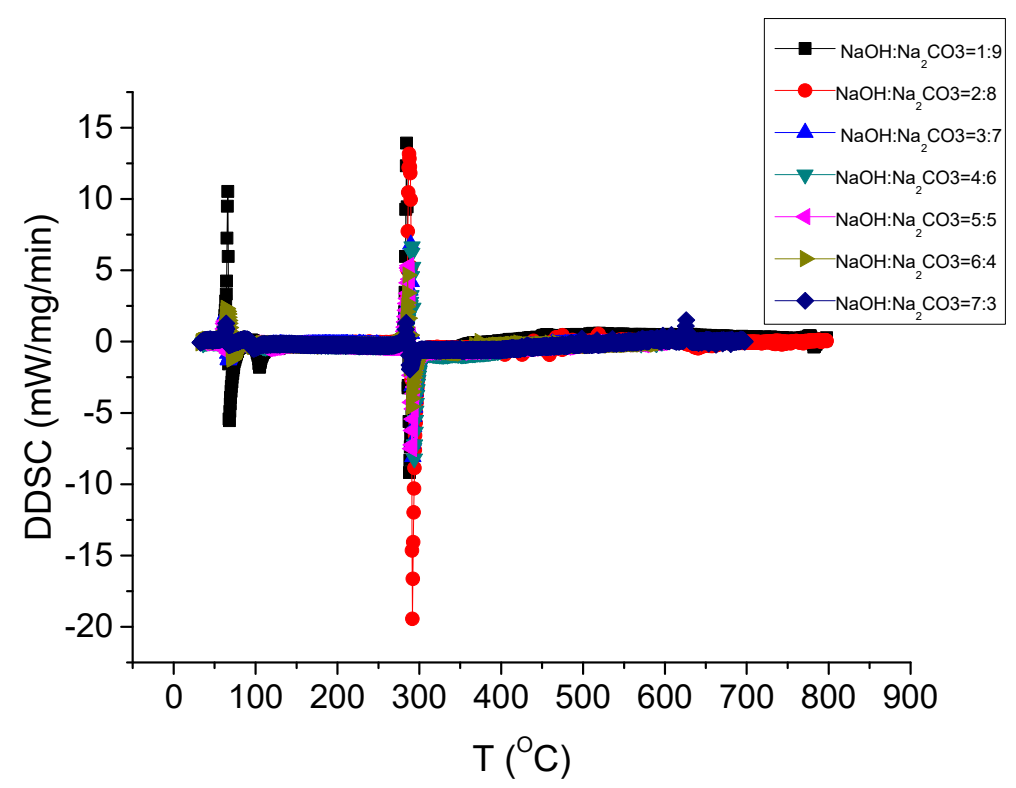

Figure 10. Melting point of a molten salts mixture with different $\mathrm{NaOH}: \mathrm{Na}_{2} \mathrm{CO}_{3}$ molar ratios. 


\subsection{Numerical Model of Raw Syngas Conditioning}

Two simultaneous processes occur when raw syngas conditioning is carried out using molten salts, as shown in Figure 3 and reactions (1)-(3). $\mathrm{CO}$ in the bubbles is converted to $\mathrm{H}_{2}$ and simultaneously generates $\mathrm{CO}_{2}$ via the homogeneous water-gas shift reaction (2). $\mathrm{CO}_{2}$ is transferred to the interface of the gas bubble and the molten mixture by mass transfer, where it reacts with $\mathrm{NaOH}$ and generates $\mathrm{Na}_{2} \mathrm{CO}_{3}$ via the heterogeneous gas-liquid reaction (1). This process contains mass transfer and chemical reactions.

\subsubsection{Model Assumptions}

Some assumptions were made to simplify the modeling process:

A. Under all experimental conditions, the static liquid height of the molten salt through which the gas bubbles passed was less than $35 \mathrm{~mm}$. The gas volume change due to the static pressure of the molten salts liquid was $\max \left(\frac{\rho_{i} g h}{P_{0}}\right) \approx 0.6 \%$, and reactions (1) and (2) did not change the total gas volume of the gas bubble. Thus, the volume change was ignored when modeling the reactions.

B. The heat capacity and heat conductivity coefficient values were large. Therefore, the molten salt's temperature variation caused by reactions (1) and (2) was ignored and it was assumed that the temperature was uniform.

C. For a specific bubble over a short time interval, the composition variation of the molten salt mixture caused by the reaction between $\mathrm{CO}_{2}$ in the bubble and $\mathrm{NaOH}$ in the molten salts mixture (reaction (1)) was negligible. Thus, during the reaction of a single bubble, the composition of the molten mixture was assumed to remain the same.

D. The bubble diameter was near a millimeter in size. According to the research of Grees [24], gas bubbles can remain stable as a spherical shape.

\subsubsection{Mass Transfer of $\mathrm{CO}_{2}$ between Gas Bubbles and Molten Salts}

Because the velocity $v_{0}$ and the Reynolds number were small, the flow field around the rising gas bubble could be described using the equation of non-detached flow around a spherical field. By ignoring the interactions between bubbles, the steady rising process of gas bubbles in molten salts can be simplified to the problem of an infinitely homogeneous axisymmetric flow. The stream function can be described as [25]:

$$
\psi=\frac{1}{2} \sin ^{2} \theta\left(r^{2}-\frac{d^{3}}{8 r}\right) .
$$

Under steady-state conditions, the composition transport equation in spherical coordinates can be written as [25]:

$$
u_{r} \frac{\partial C}{\partial r}+\frac{u_{\theta}}{r} \frac{\partial C}{\partial \theta}=D_{A B}\left[\frac{1}{r^{2}} \frac{\partial}{\partial r}\left(r^{2} \frac{\partial C}{\partial r}\right)+\frac{1}{r^{2} \sin \theta} \frac{\partial}{\partial r}\left(\sin \theta \frac{\partial C}{\partial \theta}\right)+\frac{1}{r^{2} \sin ^{2} \theta} \frac{\partial}{\partial \varphi}\left(\frac{\partial C}{\partial \theta}\right)\right] .
$$

According to the definition of a stream function:

$$
u_{r}=\frac{1}{\mathrm{r}^{2} \sin \theta} \frac{\partial \psi}{\partial \theta}, u_{\theta}=\frac{1}{r \cdot \sin \theta} \frac{\partial \psi}{\partial r} .
$$

By combining Equations (9) and (11), the mass flow at the interface of a gas bubble and the molten salts should be as follows [26]:

$$
J=\left.D_{A B}\left(\frac{\partial c}{\partial r}\right)\right|_{r=\frac{d}{2}}=D_{A B} \frac{C_{A}-C_{l}}{1.15}\left(\frac{3 v_{b}}{D_{A B} d^{2}}\right)^{\frac{1}{2}} \frac{\sin \theta}{\left(\theta-\frac{\sin 2 \theta}{\theta}\right)^{\frac{1}{3}}} .
$$


Therefore, the mass transfer of $\mathrm{CO}_{2}$ from inside the bubble to the surface of the gas bubble is as follows [27]:

$$
\frac{d n_{\mathrm{CO}_{2}}}{d t}=\int J d S=\frac{\pi d^{2}}{2} \int_{0}^{\pi} J \sin \theta d \theta=2^{\frac{5}{3}}\left(C_{A}-C_{l}\right) D_{A B}^{\frac{2}{3}} v_{0}^{\frac{1}{3}} d^{\frac{4}{3}} .
$$

In the molten salt mixture, because the time constant of chemical absorption was much larger than the mass transfer, the concentration of $\mathrm{CO}_{2} \mathrm{C}_{l}$ in the molten salts could be ignored.

3.2.3. Composition Changes in Gas Bubble by the Chemical Reaction

The Arrhenius equation of the chemical reaction rate is as follow:

$$
-\frac{d a}{d t}=A \cdot e^{-\frac{E}{R T}} \prod_{i} a_{i}^{n_{i}}
$$

At a certain time $t$, the molar concentration of $\mathrm{CO}, \mathrm{H}_{2} \mathrm{O}, \mathrm{CO}_{2}$, and $\mathrm{H}_{2}$ are $\mathrm{C}_{\mathrm{CO}^{\prime}}^{t} \mathrm{C}_{\mathrm{H}_{2} \mathrm{O}^{\prime}}^{t} \mathrm{C}_{\mathrm{CO}_{2}}^{t}$ and $\mathrm{C}_{\mathrm{H}_{2}}^{t}$, respectively. According to reaction (2), when the reactions become balanced at time $t+d t$, the molar concentration of $\mathrm{CO}, \mathrm{H}_{2} \mathrm{O}, \mathrm{CO}_{2}$, and $\mathrm{H}_{2}$ changed because of the mass transfer and chemical reactions. Furthermore, the molar concentration of the above materials are $C_{\mathrm{CO}}^{t}-\Delta a, C_{\mathrm{H}_{2} \mathrm{O}}^{t}+\frac{d C_{\mathrm{CO}_{2}}}{d t}-\Delta a$, $\mathrm{C}_{\mathrm{CO}_{2}}^{t}-\frac{d C_{\mathrm{CO}_{2}}}{d t}+\Delta a$, and $C_{\mathrm{H}_{2}}^{t}+\Delta a$, respectively.

$$
\begin{aligned}
& \mathrm{CO}+\mathrm{H}_{2} \mathrm{O} \rightarrow \mathrm{CO}_{2}+\mathrm{H}_{2} \\
& \text { Time } t \text { : } \quad \mathrm{C}_{\mathrm{CO}}^{t} \quad \mathrm{C}_{\mathrm{H}_{2} \mathrm{O}}^{t} \quad \mathrm{C}_{\mathrm{CO}_{2}}^{t} \quad \mathrm{C}_{\mathrm{H}_{2}}^{t} \\
& \text { Time } t+d t: \quad C_{\mathrm{CO}}^{t}-\Delta a \quad \mathrm{C}_{\mathrm{H}_{2} \mathrm{O}}^{t}+\frac{d \mathrm{C}_{\mathrm{CO}_{2}}}{d t}-\Delta a \quad \mathrm{C}_{\mathrm{CO}_{2}}^{t}-\frac{d C_{\mathrm{CO}_{2}}}{d t}+\Delta a \quad C_{\mathrm{H}_{2}}^{t}+\Delta a
\end{aligned}
$$

The definition of the balance constant $K_{\theta}$ at time $t+d t$ could be written as:

$$
K_{\theta}=\frac{\left(C_{\mathrm{CO}}^{t}-\Delta a\right)\left(C_{\mathrm{H}_{2} \mathrm{O}}^{t}+\frac{d C_{\mathrm{CO}_{2}}}{d t}-\Delta a\right)}{\left(C_{\mathrm{CO}_{2}}^{t}-\frac{d C_{\mathrm{CO}_{2}}}{d t}+\Delta a\right)\left(C_{\mathrm{H}_{2}}^{t}+\Delta a\right)} .
$$

When the water-gas shift reaction becomes balanced at time $t+d t$, the rates of the forward and reverse reactions become balanced:

$$
\begin{aligned}
A_{1} \cdot e^{-\frac{E_{1}}{R T}}\left(C_{\mathrm{CO}}^{t}-\Delta a\right) & \left(C_{\mathrm{H}_{2} \mathrm{O}}^{t}+\frac{d C_{\mathrm{CO}_{2}}}{d t}-\Delta a\right) \\
& =A_{2} \cdot e^{-\frac{E_{2}}{R T}} \cdot\left(C_{\mathrm{CO}_{2}}^{t}-\frac{d C_{\mathrm{CO}_{2}}}{d t}+\Delta a\right)\left(C_{\mathrm{H}_{2}}^{t}+\Delta a\right) .
\end{aligned}
$$

\begin{tabular}{|c|c|c|}
\hline Reactions & $\begin{array}{l}\text { A } \\
-\end{array}$ & $\begin{array}{c}\mathrm{E} \\
(\mathrm{kJ} / \mathrm{mol})\end{array}$ \\
\hline $\mathrm{H}_{2} \mathrm{O}+\mathrm{CO} \rightarrow \mathrm{CO}_{2}+\mathrm{H}_{2}$ & $2.75 \times 10^{10}$ & 83.8 \\
\hline $\mathrm{CO}_{2}+\mathrm{H}_{2} \rightarrow \mathrm{H}_{2} \mathrm{O}+\mathrm{CO}$ & $2.65 \times 10^{-2}$ & 0.00396 \\
\hline
\end{tabular}

The balance constant $K_{\theta}$ at $400{ }^{\circ} \mathrm{C}$ in Equation (18) can be calculated using the kinetic constant of a water-gas shift shown in Table 2:

$$
K_{\theta}=\frac{\left(C_{\mathrm{CO}}^{t}-\Delta a\right)\left(C_{\mathrm{H}_{2} \mathrm{O}}^{t}+\frac{d C_{\mathrm{CO}_{2}}}{d t}-\Delta a\right)}{\left(C_{\mathrm{CO}_{2}}^{t}-\frac{d C_{\mathrm{CO}_{2}}}{d t}+\Delta a\right)\left(C_{\mathrm{H}_{2}}^{t}+\Delta a\right)}=\frac{A_{2} \cdot e^{-\frac{E_{2}}{R T}}}{A_{1} \cdot e^{-\frac{E_{1}}{R T}}} \approx 1.47 \times 10^{-6} \ll 1 .
$$

Table 2. Kinetic parameters of a water-gas shift [28]. 
By ignoring the second-order smaller quantity, we obtain from Equation (13):

$$
\Delta \alpha=\frac{C_{\mathrm{CO}}}{C_{\mathrm{CO}}+C_{\mathrm{H}_{2} \mathrm{O}}} \frac{d_{\mathrm{CO}_{2}}}{d t} .
$$

In the present work, under all experimental conditions, the $\mathrm{CO}_{2}$ concentration was approximately $1 \%$. In addition, reactions (1) and (2) keep the total gas quantity unchanged. At the same time, during the reaction, the total mass quantity of $\mathrm{H}_{2}$ and $\mathrm{CO}$ remain the same. Thus, Equation (14) can be approximated as:

$$
\begin{gathered}
\Delta \alpha=\frac{C_{\mathrm{CO}}}{C_{\mathrm{CO}}+C_{\mathrm{H}_{2} \mathrm{O}}} \frac{d_{\mathrm{CO}_{2}}}{d t} \approx \frac{C_{\mathrm{CO}}}{C_{\mathrm{CO}}+\left(C_{0}-C_{\mathrm{CO}}-C_{\mathrm{H}_{2}}\right)} \frac{d_{\mathrm{CO}_{2}}}{d t}=\frac{C_{\mathrm{CO}}}{C_{0}-C_{\mathrm{H}_{2}}} \frac{d_{\mathrm{CO}_{2}}}{d t} \\
=\frac{C_{\mathrm{CO}}}{C_{0}-\left(C_{\mathrm{CO}, 0}+C_{\mathrm{H}_{2}, 0}\right)+C_{\mathrm{CO}}} \frac{d_{\mathrm{CO}_{2}}}{d t},
\end{gathered}
$$

or can be approximated as:

$$
\begin{aligned}
& \Delta \alpha=\frac{C_{\mathrm{CO}}}{C_{\mathrm{CO}}+C_{\mathrm{H}_{2} \mathrm{O}}} \frac{d_{\mathrm{CO}_{2}}}{d t} \approx \frac{C_{\mathrm{CO}}}{C_{\mathrm{CO}}+\left(C_{0}-C_{\left.\mathrm{CO}-C_{\mathrm{H}_{2}}\right)}\right.} \frac{d_{\mathrm{CO}_{2}}}{d t}=\frac{C_{\mathrm{CO}}}{C_{0}-C_{\mathrm{H}_{2}}} \frac{d_{\mathrm{CO}_{2}}}{d t} \\
& =\frac{C_{\mathrm{CO}, 0}+C_{\mathrm{H}_{2}, 0}-C_{\mathrm{H}_{2}}}{C_{0}-\left(C_{\mathrm{CO}, 0}+C_{\mathrm{H}_{2}, 0}\right)+C_{\mathrm{CO}}} \frac{d_{\mathrm{CO}_{2}}}{d t} \text {. }
\end{aligned}
$$

The composition change of the syngas can be described using differential equations:

$$
\left\{\begin{array}{c}
\frac{d_{\mathrm{CO}}}{d t}=-\frac{C_{\mathrm{CO}}}{C_{0}-\left(C_{\mathrm{CO}, 0}+C_{\mathrm{H}_{2}, 0}\right)+C_{\mathrm{CO}}} \frac{d_{\mathrm{CO}_{2}}}{d t}, \\
\frac{d_{\mathrm{H}_{2}}}{d t}=\frac{\left(C_{\mathrm{CO}, 0}+C_{\mathrm{H}_{2}, 0}\right)-C_{\mathrm{H}_{2}}}{C_{0}-\left(C_{\mathrm{CO}, 0}+C_{\mathrm{H}_{2}, 0}\right)+C_{\mathrm{CO}}} \frac{d_{\mathrm{CO}_{2}}}{d t},
\end{array}\right.
$$

where $d_{\mathrm{CO}_{2}}$ is the decrease in $\mathrm{CO}_{2}$ concentration caused by the mass transfer of $\mathrm{CO}_{2}$ from the gas bubble to the molten salts such that:

$$
\frac{d_{\mathrm{CO}_{2}}}{d t}=\frac{3 \times 2^{\frac{7}{3}} D_{A B}^{\frac{2}{3}} v_{0}^{\frac{1}{3}}}{\pi d^{\frac{5}{3}}} C_{\mathrm{CO}_{2}} .
$$

By integrating Equation (23), equations that describe the concentration variation of $\mathrm{CO}$ and $\mathrm{H}_{2}$ with time will be:

$$
\left\{\begin{array}{l}
k_{1}-\left\{C_{\mathrm{CO}}+k_{3} \ln \left(C_{\mathrm{CO}}\right)\right\}=\frac{d_{\mathrm{CO}_{2}}}{d t} t=k_{0} \frac{l}{d^{3}}, \\
k_{1}-\left\{C_{\mathrm{CO}}+k_{3} \ln \left(C_{\mathrm{CO}}\right)\right\}=\frac{d_{\mathrm{CO}_{2}}}{d t} t=k_{0} \frac{l}{d^{3}},
\end{array}\right.
$$

where $k_{0}=\frac{8 \times 3^{\frac{7}{3}}}{\pi}\left\{\frac{D_{A B} \mu}{\rho}\right\}, k_{1}=C_{\mathrm{CO}, 0}+k_{3} \ln \left(C_{\mathrm{CO}, 0}\right), k_{2}=C_{\mathrm{H}_{2} \mathrm{O}}^{*}+k_{3} \ln \left(C_{\mathrm{H}_{2} \mathrm{O}}^{*}\right), k_{3}=C_{0}-\left(C_{\mathrm{CO}, 0}+C_{\mathrm{H}_{2}, 0}\right)$, and $C_{\mathrm{H}_{2}}^{*}=\left(C_{\mathrm{CO}, 0}+C_{\mathrm{H}_{2}, 0}\right)-C_{\mathrm{H}_{2}}$.

The constants in Equation (23) are listed in Table 3.

Theoretically, the variation in the time-dependent $\mathrm{CO}$ and $\mathrm{H}_{2}$ concentrations can be predicted using Equation (23). Because of the lack of information on the detailed physicochemical properties of molten salts, there is no literature available for $D_{A B}, \mu$, and $\rho_{l}$. Applying the natural logarithm to both sides of Equation (26) gives:

$$
\left\{\begin{array}{c}
\ln \left\{k_{1}-\left\{C_{\mathrm{CO}}+k_{3} \ln \left(C_{\mathrm{CO}}\right)\right\}\right\}-\ln k_{0}+3 \ln d=\ln l \\
\ln \left\{k_{2}-\left\{C_{\mathrm{H}_{2}}^{*}+k_{3} \ln \left(C_{\mathrm{H}_{2}}^{*}\right)\right\}\right\}-\ln k_{0}+3 \ln d=\ln l .
\end{array}\right.
$$


Table 3. Constant values used in the model.

\begin{tabular}{ccccccccc}
\hline $\begin{array}{c}k_{1} \\
-\end{array}$ & $\begin{array}{c}k_{1} \\
-\end{array}$ & $\begin{array}{c}C_{0} \\
\mathbf{m o l} / \mathrm{L}\end{array}$ & $\begin{array}{c}C_{\mathrm{CO}, 0}+C_{\mathrm{H}_{2}, 0} \\
\mathbf{m o l} / \mathrm{L}\end{array}$ & $\begin{array}{c}C_{\mathrm{CO}, 0} \\
\mathbf{m o l} / \mathrm{L}\end{array}$ & $\begin{array}{c}\boldsymbol{k}_{3} \\
\mathbf{m o l} / \mathbf{L}\end{array}$ & $\begin{array}{c}C_{\mathrm{H}_{2} \mathrm{O}} \\
\mathbf{m o l} / \mathbf{L}\end{array}$ & $\mathbf{m}$ & $\begin{array}{c}\boldsymbol{d} \\
\mathbf{m}\end{array}$ \\
\hline-0.040 & -0.040 & 0.045 & 0.031 & 0.016 & 0.013 & 0.016 & 0.005 & 0.010 \\
\hline
\end{tabular}

Under certain conditions, while $l$ is the only variable, the experimental data should be a straight line for $\operatorname{lnl}$. As mentioned above, when gas bubbles make it through the molten mixture, the gas will keep reacting with the upper surface of the molten salts for a certain time $t_{0}$, which will be nearly the same for most of the experimental conditions. By making the time $t_{0}$ equivalent to a molten mixture static liquid height $l_{0}$, Equation (25) can be obtained:

$$
\left\{\begin{array}{c}
\ln \left\{k_{1}-\left\{C_{\mathrm{CO}}+k_{3} \ln \left(C_{\mathrm{CO}}\right)\right\}\right\}-\ln k_{0}+3 \ln d=\ln \left(l+l_{0}\right), \\
\ln \left\{k_{2}-\left\{C_{\mathrm{H}_{2}}^{*}+k_{3} \ln \left(C_{\mathrm{H}_{2}}^{*}\right)\right\}\right\}-\ln k_{0}+3 \ln d=\ln \left(l+l_{0}\right) .
\end{array}\right.
$$

Figures 11 and 12 are straight lines generated by processing experimental data using Equation (25). The real bubble diameter is related to the viscosity, plate hole diameter, temperature, and so on. There are still no published results on the relations between the bubble diameter and the above-mentioned variables. Therefore, the bubble diameter $d$ in Equation (25) was estimated using the hole diameter of plate 5 in Figure 1 [27]. The processed data are shown as straight lines in Figures 11 and 12. Straight lines fitted using experimental data that were determined using different hole diameters have the same slope but different y-intercepts. This result implies that in the molten salt liquid, the diameter of the gas bubbles did not increase linearly with the diameter of the plate holes. The relationship of the bubble diameters and the plate holes requires further study. A new set of experimental data was obtained by using a different syngas $\left(35 \% \mathrm{CO}, 30 \% \mathrm{CO}_{2}\right.$, and $\left.35 \% \mathrm{H}_{2}\right)$ and a plate hole $0.005 \mathrm{~m}$ in diameter. The new data were also processed using Equation (28) and marked as New Data(ND) in Figures 11 and 12. It can be seen that the prediction results of the equation obtained in this paper were in good agreement with the new data. Furthermore, it can also be predicted that for plates with a hole $0.005 \mathrm{~m}$ in diameter when the plate position was $105 \mathrm{~mm}$ and $225 \mathrm{~mm}$, the $\mathrm{H}_{2}$ composition of the outlet gas was $80 \%$ and $90 \%$, respectively.

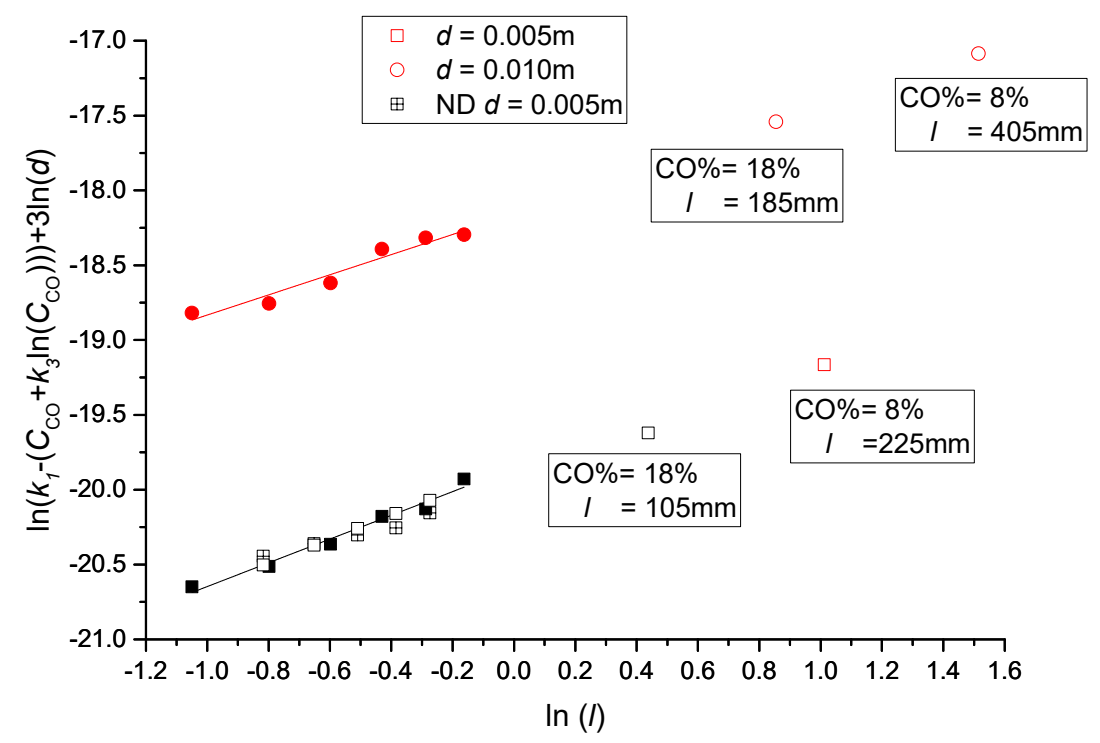

Figure 11. Fitting line of the CO content. 


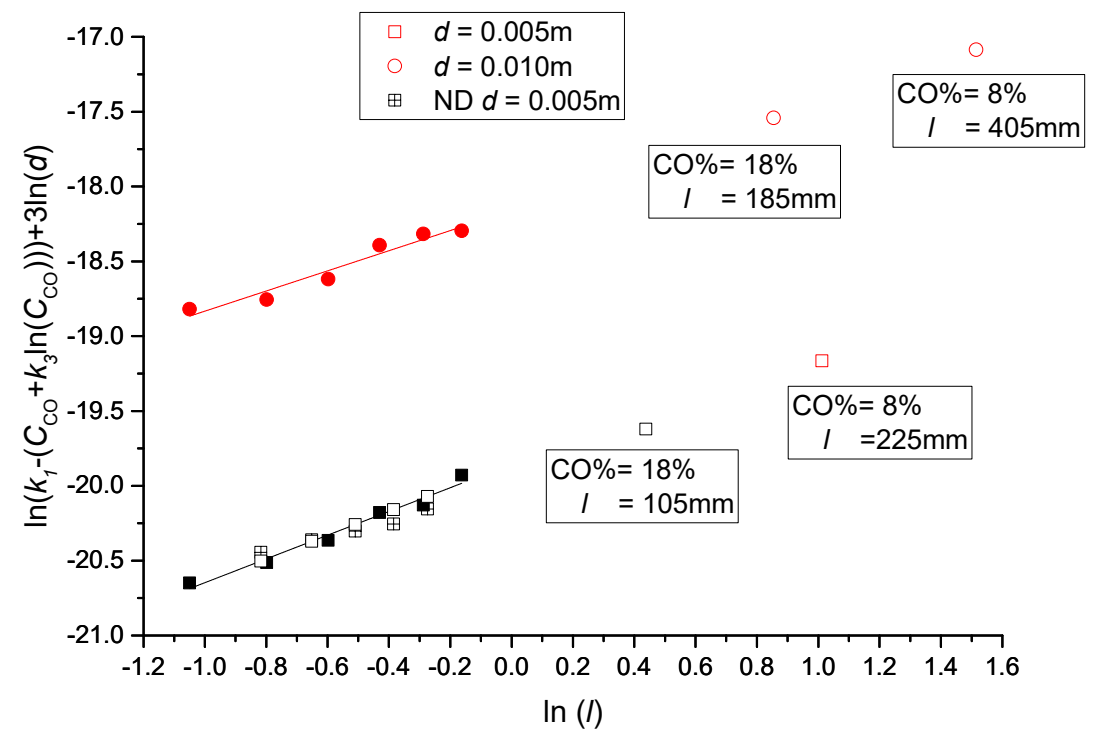

Figure 12. Fitting line of the $\mathrm{H}_{2}$ content.

The diameter of the gas bubble had less of an influence on the mass transfer process. The syngas conditioning process can be dramatically improved by raising the temperature and prolonging the reaction time by increasing the static liquid height or decreasing the superficial gas velocity.

\section{Conclusions}

(1) Temperature, superficial gas velocity, and residence time all influence raw syngas conditioning. $\mathrm{CO}$ can be converted to $\mathrm{H}_{2}$ and $\mathrm{CO}_{2}$ can be absorbed by molten salts. Under all experimental conditions, the $\mathrm{H}_{2}$ content in the gas product was dramatically higher than that in the raw syngas and the $\mathrm{CO}$ content was reduced. The $\mathrm{H}_{2} / \mathrm{CO}$ ratio increased from 0.94 to between 1.5 and 11 , which can meet the requirements of most synthetic processes. It is worth mentioning that there was minimal $\mathrm{CO}_{2}$ in the gas product.

(2) The gas product content was relatively stable throughout the 11 hours of experimentation, which shows that molten salts have great stability and potential for raw syngas conditioning. After the conditioning experiment, $\mathrm{NaOH}$ was converted to $\mathrm{Na}_{2} \mathrm{CO}_{3}$ via the absorption of $\mathrm{CO}_{2}$. The $\mathrm{NaOH}$ content in the solidified molten salts was higher in the middle and lower at both outer ends.

(3) The relationship between the syngas composition and reaction conditions, such as temperature, molten salt static liquid height, and bubble size, was modeled based on equations of turbulent flow around a sphere and chemical reaction equations. The model analysis showed that the conditioning process could be dramatically promoted by increasing the reaction temperature and prolonging the residence time, while the gas bubble diameter had less of an influence. Under the experimental conditions of the present work, the model could predict the syngas composition after the conditioning process using a molten salts mixture. Theoretical analysis of bubble movements, mass transfer, and chemical reactions were made for a single gas bubble in a static molten salt. The gas-liquid mass transfer and chemical reaction processes for the same gas bubbles was significant in chemical processes. Further studies are required for the analysis of more complex multi-gas-bubble systems.

Author Contributions: Conceptualization, X.W., Z.Z. and H.L.; methodology, X.W. and A.L.; writing-original draft preparation, X.W. and A.L.; writing—review and editing, X.W.; supervision, Z.Z.; funding acquisition, X.W. All authors have read and agreed to the published version of the manuscript.

Funding: This work was supported by the Science and Technology Program of Guangzhou (grant no. 201904010128). 
Conflicts of Interest: The authors declare no conflict of interest.

\section{Nomenclature}

$C_{A} \quad$ Concentration of substance $A$ in the syngas $\left(\mathrm{mol} \cdot \mathrm{L}^{-1}\right)$.

$C_{D} \quad$ Viscous resistance coefficient.

$C_{l} \quad$ Concentration of a certain substance in the molten salt $\left(\mathrm{mol} \cdot \mathrm{L}^{-1}\right)$.

$C_{i}^{t} \quad$ Molar concentration of substance $i$ at time $t\left(\mathrm{~mol} \cdot \mathrm{L}^{-1}\right)$.

$C_{0} \quad$ Molar concentration of all the syngas $\left(\mathrm{mol} \cdot \mathrm{L}^{-1}\right)$.

$D_{A B} \quad$ Gas-liquid mass transfer coefficient $\left(\mathrm{m}^{2} \cdot \mathrm{S}^{-1}\right)$.

$d \quad$ Diameter of the gas bubble $(\mathrm{m})$.

E Activation energy $\left(\mathrm{kJ} \cdot \mathrm{mol}^{-1}\right)$.

g Gravitational acceleration $\left(9.8 \mathrm{~m} \cdot \mathrm{s}^{-2}\right)$.

$h \quad$ Molten salts static liquid height (m).

$i \quad$ Substance $i$ in the reaction system.

$K^{\theta} \quad$ Reaction equilibrium constant.

$l \quad$ Length of plate to get into the molten salts mixture (m).

$n_{i} \quad$ Reaction order of substance $i$.

$\mathrm{P}_{0} \quad$ Atmospheric pressure $(\mathrm{Pa})$.

$\mathrm{R} \quad$ Gas constant $\left(8.317 \mathrm{~J} \cdot \mathrm{K}^{-1} \cdot \mathrm{mol}^{-1}\right)$.

$T \quad$ Reaction temperature $(\mathrm{K})$.

$v \quad$ Bubble velocity $\left(\mathrm{m} \cdot \mathrm{S}^{-1}\right)$.

$v_{0} \quad$ Terminal velocity of bubble $\left(\mathrm{m} \cdot \mathrm{S}^{-1}\right)$.

$\alpha_{i} \quad$ Molar concentration of reaction component $i\left(\mathrm{~mol} \cdot \mathrm{L}^{-1}\right)$.

$\Delta \alpha \quad$ Molar concentration variation cause by chemical reaction in time variation $\Delta t\left(\mathrm{~mol} \cdot \mathrm{L}^{-1}\right)$.

$\rho_{l} \quad$ Density of molten mixture $\left(\mathrm{kg} \cdot \mathrm{m}^{-3}\right)$.

$\mu \quad$ Viscosity of molten mixture (Pa.s).

\section{References}

1. Lewandowski, W.M.; Ryms, M.; Kosakowski, W. Thermal Biomass Conversion: A Review. Processes 2020, 8 , 516. [CrossRef]

2. Dai, S.; Zheng, Y.; Zhao, Y.; Chen, Y.; Niu, D. Molten hydroxide for detoxification of chlorine-containing waste: Unraveling chlorine retention efficiency and chlorine salt enrichment. J. Environ. Sci. 2019, 82, 192-202. [CrossRef]

3. Niu, M.; Huang, Y.; Jin, B.; Liang, S.; Dong, Q.; Gu, H.; Sun, R. A novel two-stage enriched air biomass gasification for producing low-tar high heating value fuel gas: Pilot verification and performance analysis. Energy 2019, 173, 511-522. [CrossRef]

4. Li, J.; Han, D.; He, T.; Liu, G.; Zi, Z.; Wang, Z.; Wu, J.; Wu, J. Nanocrystal H[Fe, Al]ZSM-5 zeolites with different silica-alumina composition for conversion of dimethyl ether to gasoline. Fuel Process. Technol. 2019, 191, 104-110. [CrossRef]

5. $\mathrm{Hu}, \mathrm{Y}$.; Lu, H.; Liu, W.; Yang, Y.; Li, H. Incorporation of $\mathrm{CaO}$ into inert supports for enhanced $\mathrm{CO}_{2}$ capture: $\mathrm{A}$ review. Chem. Eng. J. 2020, 396. [CrossRef]

6. Doranehgard, M.H.; Samadyar, H.; Mesbah, M.; Hossein, S.; Mohammad, M.; Pouya, H.; Saman, S. High-purity hydrogen production with in situ $\mathrm{CO}_{2}$ capture based on biomass gasification. Fuel 2017, 202, 29-35. [CrossRef]

7. Lee, K.B.; Michael, G.B.; Hugo, S.C.; Shivaji, S. Performance of $\mathrm{Na}_{2} \mathrm{O}$ promoted alumina as $\mathrm{CO}_{2}$ chemisorbent in sorption-enhanced reaction process for simultaneous production of fuel-cell grade $\mathrm{H}_{2}$ and compressed $\mathrm{CO}_{2}$ from synthesis gas. J. Power Sources 2008, 176, 312-319. [CrossRef]

8. Kinoshita, C.M.; Turn, S.Q. Production of hydrogen from bio-oil using $\mathrm{CaO}$ as a $\mathrm{CO}_{2}$ sorbent. Int. J. Hydrogen Energy 2003, 28, 1065-1071. [CrossRef]

9. Li, F.; Zhao, Z.; Li, H.; Ma, X.; Chen, Y. Study on Gasification Characteristics of Electronic Waste Plastic in Molten Salts. J. Combust. Sci. Technol. 2005, 11, 470-474.

10. Yaw, D.Y.; Yong, X. Catalytic Gasification of Coal Using Eutectic Salt Mixtures. Final Tech. Rep. 2001. [CrossRef] 
11. Tomkute, V.; Solheim, A.; Sakirzanovas, S.; Espen, O. Reactivity of $\mathrm{CaO}$ with $\mathrm{CO}_{2}$ in molten $\mathrm{CaF}_{2}-\mathrm{NaF}$ Formation and decomposition of carbonates. Energy Sci. Eng. 2016, 4, 205-216. [CrossRef]

12. Tang, H.; Xu, M.; Hu, H.; Yang, F.; Yang, Y.; Liu, H.; Li, X.; Yao, H. In-situ removal of sulfur from high sulfur solid waste during molten salt pyrolysis. Fuel 2018, 231, 489-494. [CrossRef]

13. Wang, X.; Zhao, Z.; Li, H.; Liu, A.; Wu, H. Method for Purification and Conditioning of Crude Syngas Based on Properties of Molten Salts; Guangzhou Institute of Energy Conversion, Chinese Academy of Sciences: Guangzhou, China, 2014.

14. Li, F.; Wu, Y.; Zhao, Z.; Li, H.; Chen, Y. Experimental study on the effect of eutectic salts on pyrolysis of waste printed circuit boards (PCB). J. Fuel Chem. Technol. 2007, 548-552.

15. Jiang, H.; Wu, Y.; Fan, H.; Ji, J. Hydrogen Production from Biomass Pyrolysis in Molten Alkali. AASRI Procedia 2012, 3, 217-223. [CrossRef]

16. Guo, D.; Wu, S.; Liu, B.; Yin, X.; Yang, Q. Catalytic effects of $\mathrm{NaOH}$ and $\mathrm{Na}_{2} \mathrm{CO}_{3}$ additives on alkali lignin pyrolysis and gasification. Appl. Energy 2012, 95, 22-30. [CrossRef]

17. Wang, X.; Zhao, Z.; Liu, A.; Li, C.H. Experimental study on toluene cracking in eutectic salts. J. Fuel Chem. Technol. 2011, 39, 675-681.

18. Shiying, L.; Michiaki, H.; Yoshizo, S.; Hiroyuki, H. Continuous experiment regarding hydrogen production by coal/CaO reaction with steam (I) gas products. Fuel 2004, 83, 869-874.

19. Sada, E.; Katoh, S.; Yoshll, H.; Yamanishi, H.; Nakanishi, A. Performance of the Gas Bubble Column in Molten Salt Systems. Ind. Eng. Chem. Process Des. Dev. 1984, 23, 151-154. [CrossRef]

20. Kulkarni, A.A.; Joshi, J.B. Bubble formation and bubble rise velocity in gas-liquid systems: A review. Ind. Eng. Chem. Res. 2005, 44, 5873-5931. [CrossRef]

21. Zheng, Y.; Jia, Q.; Fang, X. Mechanics; Higher Education Press: Beijing, China, 2002.

22. David, R.L. CRC Handbook of Chemistry and Physics; Internet Version; CRC Press: Boca Raton, FL, USA, 2005.

23. Liu, G.; Ma, L.; Liu, J. Handbook of Chemistry and Chemical Properties-Inorganics; Chemical Industry Press: Beijing, China, 2002.

24. Dai, G.; Chen, M. Chemical Fluid Mechanics; Chemical Industry Press: Beijing, China, 2005.

25. Pan, W. Basic Fluid Mechanics; Mechanical Industry Press: Beijing, China, 1982.

26. Guo, K. Computational Heat Transfer; University of Science and Technology of China Press: Hefei, China, 1988.

27. Tian, H.; Jin, L.; Ding, Z.; Xie, T. Coupling model for bubble rise and mass transfer process in liquid. J. Chem. Ind. 2010, 61, 15-21.

28. Watanabe, H.; Otaka, H. Numerical simulation of coal gasification in entrained flow coal gasifier. Fuel 2006, 85, 1935-1943. [CrossRef]

(C) 2020 by the authors. Licensee MDPI, Basel, Switzerland. This article is an open access article distributed under the terms and conditions of the Creative Commons Attribution (CC BY) license (http://creativecommons.org/licenses/by/4.0/). 